\title{
Effect of Simulation methodology on variable efficiency of Bi-directional Heat Recovery Ventilator
}

\author{
Younhee Choi ${ }^{1}$, Beungyong Park ${ }^{2}$, Doosam Song ${ }^{3}$ \\ ${ }^{1}$ Graduate School of Sungkyunkwan University, Suwon, Republic of Korea \\ ${ }^{2}$ Korea Conformity Laboratories, Juncheon-gun, Republic of Korea \\ ${ }^{3}$ Department of Architectural Engineering, Suwon, Republic of Korea
}

\begin{abstract}
Recently, Energy Recovery Ventilator (ERV) has been installed to secure energy saving and Indoor Air Quality (IAQ) in multi-residential building. A lot of effort has been devoted to the development of various types of ERV systems for the purpose of improving heat exchange efficiency, preventing condensation problems in the elements, and increasing usability etc. Among various ERV systems, a ventilation system using a new concept called Alternating Ventilation (AC ventilation) such as Bidirectional Heat Recovery Ventilator (BdHRV) has been developed and broadly installed.

The performance of a heat (sensitive / latent / enthalpy) recovery ventilators are defined as a fixed value by measurement under specified indoor and outdoor conditions, and this value used as input data for the energy simulation.

However, the heat exchange efficiency of Bi-directional Heat Recovery Ventilator (BdHRV) in which air supply and exhaust process are repeated over a period of time and heat is accumulated in the exhaust mode through the heat storage element and heat is released in the supply process is not constant but varies with time.

In this study, the transient heat exchange efficiency of BdHRV was measured with test chamber measurement. The simulation method considering the transient heat exchange characteristics of BdHRV has been proposed. The effect of ventilation with BdHRV on heating/cooling energy usage are analyzed.
\end{abstract}

\section{Introduction}

Ventilation is the process of supplying air to or removing air from a space for the purpose of controlling indoor air contaminant levels, humidity, or temperature within space (Ashrae 2016). Ventilation is the most effective approach to providing acceptable indoor air quality and to increase the work performance (Wargocki et al., 1999; Daisey, Angell, and Apte, 2003). However, there is a trade-off between energy saving and ventilation or IAQ in contemporary building practice. Increasing the ventilation rate will improve the indoor air quality, but increased ventilation rate will contribute to an increase of the cooling and heating loads on buildings (Choi et al., 2018). Two main strategies exist in contemporary building practice that allow to reconcile these opposing interests, namely the use of heat recovery units and implementation of demand controlled ventilation (Laverge et al., 2011).

Especially in residential building, where central HVAC system is rarely equipped, split-type air-conditioner is commonly installed. However, split-type air-conditioner is not able to introduce the fresh air. Due to this reason, application of energy recovery ventilator (ERV) is one of ideal solution to this issue in residential building and ERV comes into widespread in Europe and Asia countries (Fehrm, Reiners, and Ungemach, 2002; Zhou, Wu, and Wang, 2007; Dieckmann, Roth, and Brodrick, 2003; Liu et al., 2010; Han et al., 2013).

Heat recovery term is referring to an air-to-air heat or energy recovery system which is defined as the process of recovering energy (heat/mass) from a stream at a high temperature to a low temperature stream that is effective and economical to run (Riffat and Gan, 1998). A typical heat recovery system in building consists of ducts for incoming fresh air and outgoing stale air, a heat exchanger core, where heat or energy is transferred from one stream to the other and two blower fans; one is to exhaust stale air and supply fresh air via the heat exchanger core (Mardiana-Idayu and Riffat, 2012).

While in industries, it is abbreviated as HRV (heat Recovery Ventilation) or ERV (Energy Recovery Ventilation) and became a general use within them. There are many different types of heat recovery systems are available for transferring energy from the exhaust air to the supply air or vice versa (Fehrm, Reiners, and Ungemach, 2002; El-Baky and Mohamed, 2007; Juodis, 2006). Specifically, heat recovery or air-to-air heat recovery systems are made in various types, sizes, configurations and flow arrangements. There are many types of heat recovery units which are in use in building applications and these types of heat recovery systems are depending on the heat exchanger core (ex. Fixed-plate, run-around, Rotary wheel) (Mardiana-Idayu and Riffat, 2012; ASHRAE 2000).

Conventional ventilators need two sets of incoming and outgoing airstreams to exchange energy simultaneously. Usually, four ducts are connected to an HRV, i.e., for outside air (OA), supply air (SA), return air (RA), and exhaust air (EA). Ductworks are complicated and troublesome, especially when there is not enough clear space above a ceiling panel for the supply and exhaust ducts to cross each other (Han and Kwon, 2006). 


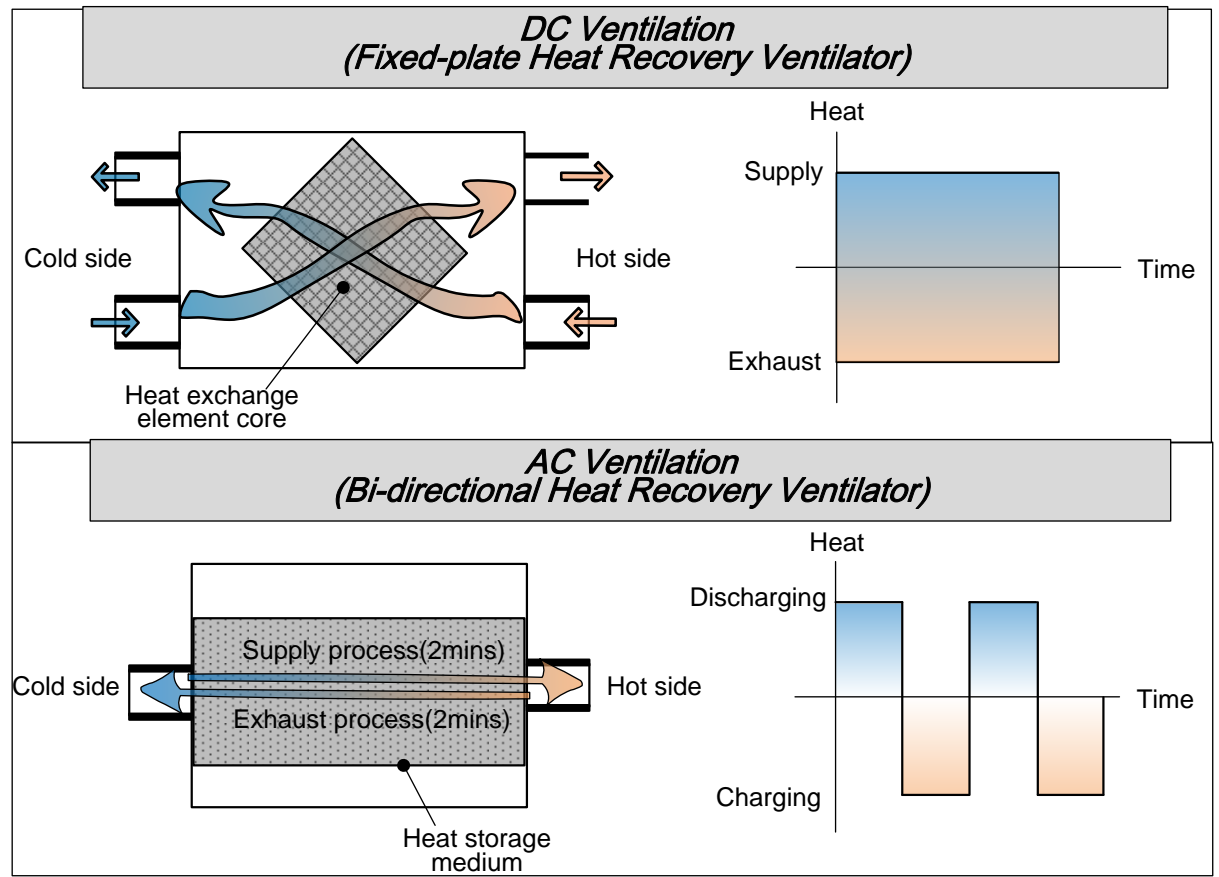

Figure 1: Concept of Fixed-plate HRV and Bi-directional HRV

Moreover, frost formation in exchangers is common in cold regions where the outdoor temperature is below $10^{\circ} \mathrm{C}$ for the majority of the cold season. And it can lead to some critical problems, such as partial or blockage of air flow passages, increase in pressure drop through the exchanger or decrease in air flow rate, increase in electric power of the fans and decrease in the heat transfer rate between the two air streams and draught in the space due to low supply air temperatures (Nasr et al., 2014).

Various advanced ventilation systems, control methods and material of element cores have been studied and developed to solve these problems, improve the heat exchange efficiency of the ERV system and increase the usability. Vapour permeable core material such as polymerized paper advances in the vapour transfer to separate moisture from the vapour / air mixture owing to their strong affinity to the water molecule are suggested(Zhang and Niu, 2001; Nasif et al., 2010; Huizing, 2016; Beattie et al., 2018; Pan et al., 1978). Hybrid ventilation using heat storage material was proposed by (Kwon et al., 2013) to reduce the ventilation load. Also ductless HRV system using heat storage material which is favourable for remodellig have been proposed(Ireland).

Han introduced an inhaling/exhaling heat recovery ventilator using the concept of Alternating Current ventilation and investigated its effects on ventilation performance of a room with measurement and Computational fluid dynamics simulations(Han and Kwon, 2006). A breathing HRV is an HRV of a new kind using the concept of Alternating-Current (AC) ventilation. $A C$ ventilation is ventilation with the airflow directions reversed periodically. It has the advantage of using a single-duct system for both supply and exhaust purposes. The thermal storage medium is charged during an exhaust process and discharged during a supply process. Figure 1 compares the mechanisms of conventional DC ventilation and $\mathrm{AC}$ ventilation.

This kind of Bi-directional Heat Recovery Ventilator (BdHRV) shows its own variable efficiency due to the characteristics of the system. Han and Kwon didn't focus on its efficiency, but more focused on to investigate the system parameter and ventilation efficiency. And in this paper, heat exchange efficiency of BDHRV showed between 10 100\% according to the parameter (Han and Kwon, 2006).

However, as a prescriptive method to investigate heat exchange efficiency, the performance of a heat (sensitive / latent / enthalpy) recovery ventilator is defined as a fixed value by measurement under specified indoor and outdoor conditions and entered as input data for the energy simulation method (Ashrae 2013; "KS B 6879-Heat Recovery Ventilators" 2017).

In this study, seasonal variable efficiency of BdHRV using the concept of AC ventilation were defined with test chamber measurement. With experimental results, simulation methodology considering the characteristics of the AC ventilation system has been proposed and its effect on heating/cooling energy usage are compared with the prescriptive method.

\section{Variable efficiency of Bi-directional Heat Recovery Ventilator (BdHRV)}

Conventional ventilators such as fixed plate type need two sets of incoming and outgoing airstreams to exchange energy simultaneously. This corresponds to Direct Current Ventilation (DC Ventilation), which is a ventilation with constant air flow and direction. Usually, four ducts are connected to an HRV unit. On the contrary, BdHRV using AC ventilation is a way to recover heat using a single duct, using alternating ventilation to separate the supply and exhaust processes over time. In a 
Table 1: Measurement conditions

\begin{tabular}{|c|c|c|c|c|}
\hline \multirow{2}{*}{} & \multicolumn{2}{|c|}{ Indoor condition } & \multicolumn{2}{c|}{ Outdoor condition } \\
\cline { 2 - 5 } & $\begin{array}{c}\text { Drybulb, } \\
{ }^{\circ} \mathrm{C}\end{array}$ & $\begin{array}{c}\text { Wetbulb, } \\
{ }^{\circ} \mathrm{C}\end{array}$ & $\begin{array}{c}\text { Drybulb, } \\
{ }^{\circ} \mathrm{C}\end{array}$ & $\begin{array}{c}\text { Wetbulb, } \\
\mathrm{OC}\end{array}$ \\
\hline Cooling & $24 \pm 0.3$ & $\begin{array}{c}17 \pm 0.2 \\
(49.6 \%)\end{array}$ & $35 \pm 0.3$ & $\begin{array}{c}24 \pm 0.2 \\
(40.3 \%)\end{array}$ \\
\hline Heating & $22 \pm 0.3$ & $\begin{array}{c}13.9 \pm 0.2 \\
(40.0 \%)\end{array}$ & $2 \pm 0.3$ & $\begin{array}{c}0.4 \pm 0.2 \\
(75.1 \%)\end{array}$ \\
\hline
\end{tabular}

sense, it is quite similar to a rotary type heat regenerator (Han and Kwon, 2006). The concept of AC ventilation coupled with a heat storage mechanism can be found elsewhere. Old adobe huts consist of porous mud walls through which air can be infiltrated or exfiltrated depending on the indoor-outdoor pressure difference. In winter, cold outdoor air is warmed up while blowing in through a warmed porous wall on the windward side. When the wind direction changes, warm indoor air heats the wall back up while blowing out through the wall. The same principle can be found in the human respiration process. While air is inhaled and exhaled, heat is stored and retrieved to and from the respiratory tract walls. The mechanism prevents cold air getting deep into lungs directly (Han and Kwon, 2006).

BdHRV proposed in this study is consist of single duct, back flow prevent damper and heat storage medium for both supply and exhaust purposes. Accordingly, it is possible to reduce the unit price and installation cost of the material through the single duct, and to prevent the condensation by blocking the inflow of air when the system is not operated by the backflow prevention damper. In addition, it is possible to expect reduction of indoor heating and cooling load and ventilation load by using heat recovery element (composed of alumina, synthetic metal, charcoal, etc.).

Then, how the heat exchange efficiency of ERV/HRV are quantified? The heat or enthalpy exchange performance of conventional Air to Air energy recovery heat exchangers can be calculated from the temperatures, humidity, and flow rate. According to ASHRAE Standard 84(84: 2013) and AHRI Standard 1060(AHRI 2018), the effectiveness of the heat or enthalpy of a system can be expressed by the conditions of the supply air (SA), return air (RA), and outdoor air (OA) as follows:

$$
\varepsilon=\frac{\dot{m}_{s}\left(\mathrm{x}_{1}-\mathrm{x}_{2}\right)}{\dot{m}_{\min }\left(\mathrm{x}_{1}-\mathrm{x}_{3}\right)}
$$

where, $\varepsilon$ is the sensible or total effectiveness [-], $\mathrm{x}_{1}$ is the OA temperature $\left[{ }^{\circ} \mathrm{C}\right]$ or enthalpy $[\mathrm{kJ} / \mathrm{kg}], \mathrm{x}_{2}$ is the

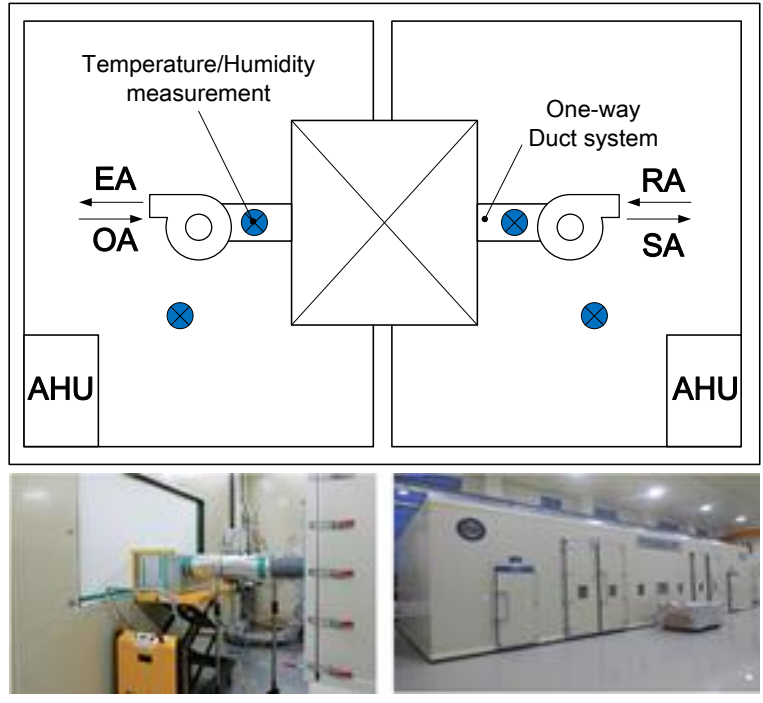

Figure 2 : Measurement configuration

SA temperature $\left[{ }^{\circ} \mathrm{C}\right]$ or enthalpy $[\mathrm{kJ} / \mathrm{kg}], \quad \mathrm{x}_{3}$ is the RA temperature $\left[{ }^{\circ} \mathrm{C}\right]$ or enthalpy $[\mathrm{kJ} / \mathrm{kg}], \dot{m}_{s}$ is the supply air flow rate $\left[\mathrm{m}^{3} / \mathrm{h}\right]$, and $\dot{m}_{\min }$ is the lower of the exhaust or supply air flow rate $\left[\mathrm{m}^{3} / \mathrm{h}\right]$. The two air flow rates had approximately equal values for the ventilation system in this study. Assuming the same flow rate across the ventilation system, the sensible effectiveness can be expressed as

$$
\varepsilon_{S}=\frac{T_{O A}-T_{S A}}{T_{O A}-T_{R A}} \times 100[\%]
$$

and the latent effectiveness as

$$
\varepsilon_{l}=\frac{W_{O A}-W_{S A}}{W_{O A}-W_{R A}} \times 100[\%]
$$

and the total effectiveness as

$$
\varepsilon_{T}=\frac{h_{O A}-h_{S A}}{h_{O A}-h_{R A}} \times 100[\%]
$$

where $\varepsilon_{S}$ is the sensible effectiveness, $\varepsilon_{l}$ is the latent effectiveness, $\varepsilon_{T}$ is the total effectiveness, $T$ is the temperature of air, $W$ is the humidity ratio of air, and $h$ is the enthalpy of air. The subscript $O A$ is used for the outdoor air, $S A$ for the supply air, and $R A$ for the return air.

This means, heat exchange efficiency is defined as a fixed value for fixed indoor and outdoor temperature / humidity conditions. In addition, fixed efficiency values are entered to the input conditions simply on the energy simulation to

\begin{tabular}{|c|c|c|c|}
\hline Model & Purpose & Specifications & Locations \\
\hline \multirow{2}{*}{$\begin{array}{c}\text { CHINO } \\
\text { (PT100 A Class) }\end{array}$} & Drybulb temperature & $\begin{array}{c}\text { Measurement range of }-30 \text { to }+70^{\circ} \mathrm{C} \text {, accuracy of } \pm 0.1^{\circ} \mathrm{C} \text {, } \\
\text { resolution is } 0.1^{\circ} \mathrm{C} \text {. }\end{array}$ & \multirow{3}{*}{$\begin{array}{l}\text { Exhaust/supply air for the } \\
\text { ventilation system, } \\
\text { Outdoor air, } \\
\text { Indoor air }\end{array}$} \\
\hline & Wetbulb temperature & $\begin{array}{c}\text { Measurement range of }-30 \text { to }+70^{\circ} \mathrm{C} \text {, accuracy of } \pm 0.1^{\circ} \mathrm{C}, \\
\text { resolution is } 0.1^{\circ} \mathrm{C} \text {. }\end{array}$ & \\
\hline $\begin{array}{l}\text { YOKOGAWA } \\
\text { MX100 }\end{array}$ & $\begin{array}{c}\text { Data logger } \\
\text { (Data acquisition unit) }\end{array}$ & $\begin{array}{c}\text { Voltage range of -60.00 to } 60.00 \mathrm{mV} \text { accuracy of } \pm 0.05 \% \\
\text { resolution is } 0.01 \mathrm{mV} \text {. }\end{array}$ & \\
\hline $\begin{array}{l}\text { YOKOGAWA } \\
\text { WT-333 }\end{array}$ & $\begin{array}{c}\text { Power meter } \\
\text { (Energy consumption) }\end{array}$ & $\begin{array}{l}\text { DC power measurement accuracy } 0.1 \% \text { of reading }+0.2 \% \text { of } \\
\text { range }\end{array}$ & System \\
\hline
\end{tabular}
evaluate the annual energy consumption of the heat exchange ventilation system (Klein et al., 2009).

\section{Table 2: Summary of instrumentation}


However, this AC ventilation system is expected to have a variable value of heat exchange efficiency rather than a fixed value in the process of storing and discharging heat due to the characteristics of the system. If wrong efficiency is entered considered to the simulation method to evaluate the annual energy consumption, it can be results in significant error(Choi et al., 2018).

Variable heat exchange efficiency of fixed-plate ERV according to indoor and outdoor conditions under actual operating conditions were defined with field measurement(Choi et al., 2018). However, there is not yet a definition on its efficiency in $\mathrm{AC}$ ventilation systems which shows the transient efficiency.

\section{Quantification of Efficiency on Bi-directional Heat Recovery Ventilator (BdHRV)}

\section{Experimental setup}

In this study, to evaluate the performance of the ventilation system, the experiments were performed according to the standard of KS B 6879 which defines the measurement method for evaluating the performance of the Energy Recovery Ventilation system("KS B 6879Heat Recovery Ventilators" 2017).

HRV was installed in a chamber composed of indoor and outdoor sides, and the points of dry bulb temperature and wet bulb temperature were as shown in Figure 2. The power consumption of the system was also measured to obtain the input data of the simulation and the specification of measurement instruments are illustrated in Table 2. The airflow of the system was fixed at $150 \mathrm{CMH}$ and the experiment was performed. The heat exchange efficiency test conditions and details of the measuring equipment are shown in Table 1-2.

\section{Experimental results}

The results of the heat exchange efficiency test of the bidirectional heat recovery ventilator are shown in Figure 34. The indoor / outdoor temperature is shown to be constant as described in Table 1. Since separated supply process and exhaust process are periodically performed at intervals of 120 seconds through the heat storage element, the temperature of the supply air linearly changes according to the mode operation. And the heat exchange efficiency also changes accordingly.

In cooling season, the warm outside air temperature decr eases while pass the heat storage medium, which is coole $\mathrm{d}$ through the exhaust process. When the system turns to the supply process, cooled supply air flow to indoor and it increases with the time. Because this transient operation condition, heat exchange efficiency is gradually lowered as time passes in the supply process. And this results are shown in Figure 3.

In the same way, it can be seen that the heat exchange efficiency is gradually lowered with the passing of the cold outside air through the warmed heat storage medium during the heating season. And the tendency of variable heat exchange efficiency in heating season is illustrated in Figure 4.

To summarize the results, the measurements showed that the heat exchange efficiency was not constant because of the inherent characteristics of BdHRV, which appears to be periodically. The transient heat exchange efficiency according to the elapsed time on heating and cooling
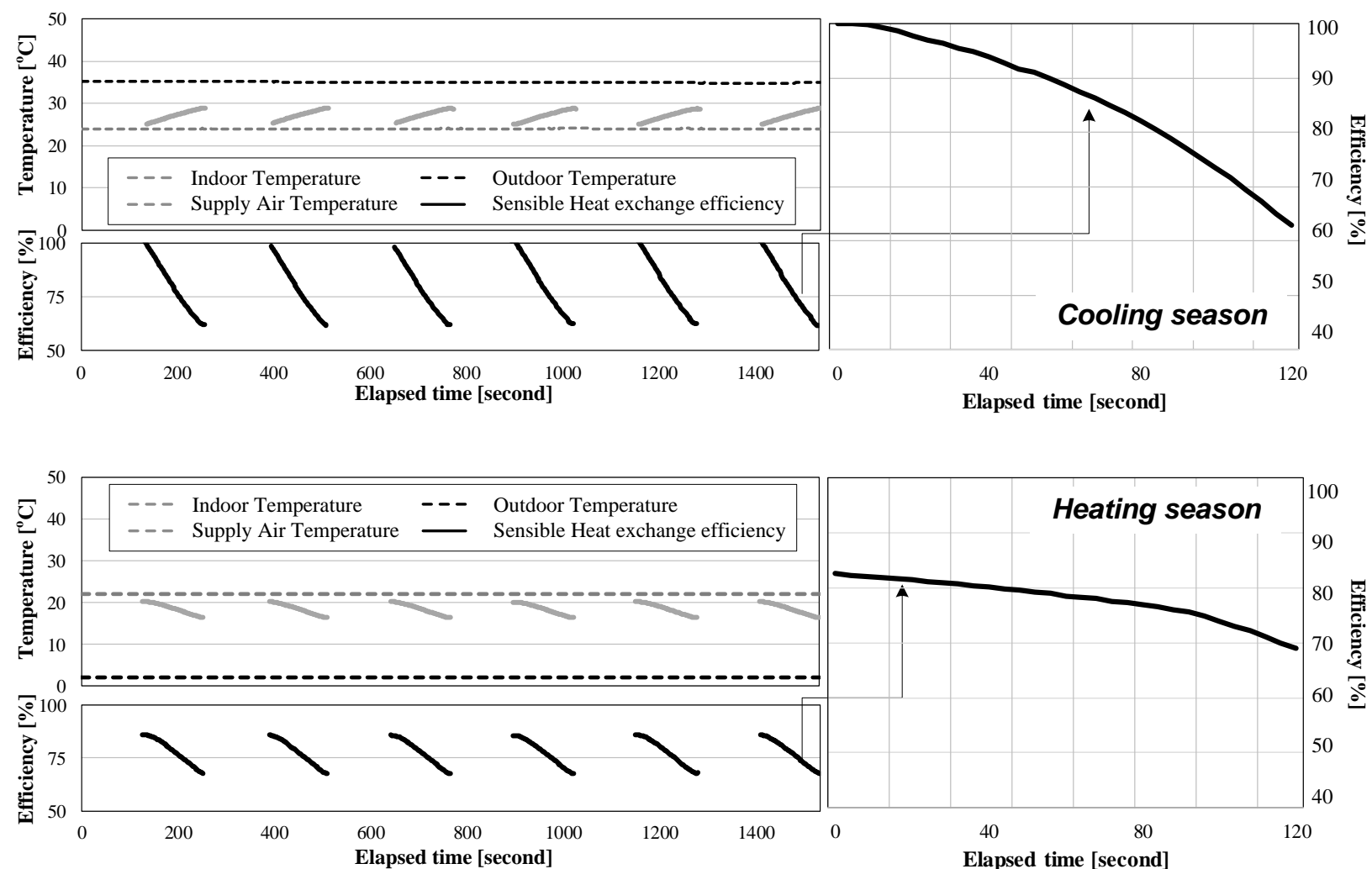
Table 3: Case configuration

\begin{tabular}{|c|c|c|c|c|c|}
\hline & ERV system & Sensible heat exchange efficiency & $\begin{array}{c}\text { Power } \\
\text { consumption }\end{array}$ & Air flow rate \\
\hline \multirow{2}{*}{ Case1 } & $\begin{array}{c}\text { Fixed-plate } \\
\text { (DC ventilation) }\end{array}$ & $\begin{array}{c}74 \% \text { (cooling) } \\
79 \% \text { (heating) }\end{array}$ & $68 \mathrm{~W}$ & -Ideal heating \\
system & $(\mathrm{COP}: 3.3)$ \\
Case2 & $\begin{array}{c}\text { Bi-directional } \\
\text { (AC ventilation) }\end{array}$ & $\begin{array}{c}62.90 \sim 100.00 \% \text { (cooling) } \\
69.48 \sim 85.94 \% \text { (heating) }\end{array}$ & $\begin{array}{c}\text { supply: } 44 \mathrm{~W} \\
\text { exhaust: } 46 \mathrm{~W} \\
\text { (Measured) }\end{array}$ & $\begin{array}{c}\text { CMH } \\
\text { (COP : 3.7) }\end{array}$ \\
\hline
\end{tabular}

Table 4: Simulation conditions

\begin{tabular}{|c|c|c|}
\hline Weather data & \multicolumn{2}{|c|}{ Seoul.TMY2 } \\
\hline $\begin{array}{c}\text { Simulation du } \\
\text { ration }\end{array}$ & Cooling & August \\
\cline { 2 - 3 } $\begin{array}{c}\text { Indoor conditi } \\
\text { on }\end{array}$ & Heating & January \\
\cline { 2 - 3 } & Cooling & $\begin{array}{c}\mathrm{DT}=24^{\circ} \mathrm{C} \text { and } \\
\mathrm{RH}=50 \% \\
\left(\mathrm{WT}=17.03{ }^{\circ} \mathrm{C}\right)\end{array}$ \\
\hline Heating gain & $\begin{array}{c}\mathrm{DT}=22^{\circ} \mathrm{C} \text { and } \\
\mathrm{RH}=40 \% \\
\left(\mathrm{WT}=13.6^{\circ} \mathrm{C}\right)\end{array}$ \\
\hline Lighting & Person & $\begin{array}{c}\text { Sensible heat }: 65 \mathrm{~W}, \\
\text { Latent heat }: 55 \mathrm{~W}\end{array}$ \\
\hline Equipment & \multicolumn{2}{|c|}{$4.3 \mathrm{~W} / \mathrm{m}^{2}$} \\
\hline \multirow{2}{*}{\begin{tabular}{c}
$6 \mathrm{~W} / \mathrm{m}^{2}$ \\
\hline Infiltration
\end{tabular}} & \multicolumn{2}{|c|}{$\begin{array}{c}\text { (Orme } \mathrm{cm}^{2} / \mathrm{m}^{2} @ 10 \mathrm{~Pa} \text { (Tight) } \\
\text { Tament, and Wilson } 1998 ;\end{array}$} \\
\hline Time step & \multicolumn{2}{|c|}{$4 \mathrm{sec}$} \\
\hline
\end{tabular}

season vary between about $62.90 \%$ and $100 \%$ and $69.48 \%$ and $85.94 \%$, respectively in constant indoor and outdoor conditions.

\section{Simulation}

\section{Simulation conditions}

To evaluate the effect of a variable heat exchange rate, the measured variable effectiveness was incorporated into simulation. Simulation condition is illustrated in Table 4.

Trnsys software was used in conjunction with Trnflow to analyze the air flow according to the characteristics of the bi-directional HRV operating the exhaust process and the supply process separately (Hiller et al., 2002; Klein et al., 2009). In other words, airtightness performance at the tight level defined by (Tamura, 2008) was implemented to realize inflow and outflow of air according to the pressure difference condition. To compare the reasonable heating and cooling load of each cases, air flow rate was set to 15 $\mathrm{CMH}$ in terms of the $0.5 \mathrm{ACH}$ of the room. Also, the time step was narrowly defined at intervals of 4 seconds in order to appropriately consider the system to be operated repeatedly at intervals of 120 seconds. Indoor condition was defined as experimental condition. weather condition data of Seoul area was used for outdoor condition.

Two cases were analyzed in this study to compare the heating load and heating energy consumption of the building depending on either fixed or variable heat exchange efficiency of the ERV and it is shown in Figure 3 .

Case1 involves constant heat exchange effectiveness, as per the conventional simulation method. Also Case1 represents the heat exchange effficiency which is defined with the prescriptive measurement method. This means that both the $\mathrm{AC}$ ventilation and the $\mathrm{DC}$ ventilation can only be achieved when the efficiency is quantified by the conventional measuring method. The heat exchange efficiency performance of Case 1 is derived from the results of the actual fixed-plate heat exchanger test report results which is similar to the mean value of the variable heat exchange value (Case2). Comparison between Case1 and Case 2 has the symbolic meaning, error that simulator and performance evaluation agency can make with the conventional method- both on simulation and measurement.

As a conventional simulation method (Case1) for ERV modeling in energy building simulation, fixed heat exchange efficiency values (Sensible, Latent, Total) are entered as input data, which is the performance test results provided by the manufacturers. Using the fixed efficiencies of ERV, the supply air temperature and humidity of ERV are determined by simple calculation as a function of Eqs. (2)-(4). Case 2 represents variable heat exchange effectiveness based on the measurements performed in this study. Main consideration on simulation methods are as : (1) Intentional / Unintentional airflow rate (Indoor and Outdoor), (2) Airflow direction, (3) Implementation of variable efficiency on simulation method and (4) Validation with the measurement results.

\section{Simulation results}

The variation efficiency values defined by the measure were implemented in the simulations, and the difference from the measurement results was shown to be RMSE $0.328(0.57 \%$ error rate).

Simulation results on Indoor air, Outdoor air, Supply air and the sensible heat exhchange efficiency of each cases are shown on Figure 5-6. In Case1, the sensible heat exchange efficiency and supply air temperature are constant due to the application of the fixed efficiency. On the other hand, the result of Case 2 shows the supply air temperature which varies with the elapsed time due to the implementation of the variable efficiency.

And as mentioned in the simulation condition section, envelope condition in simulation was designed to 


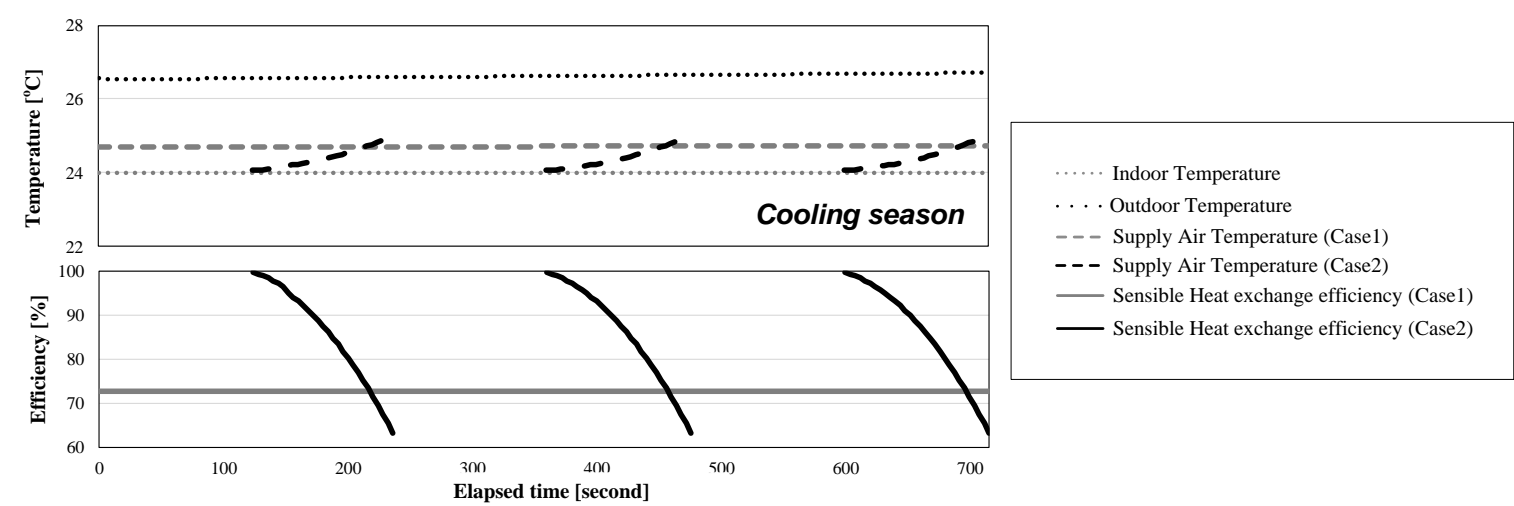

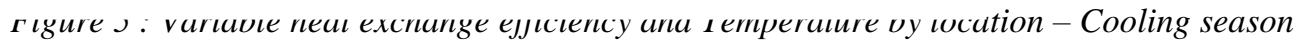

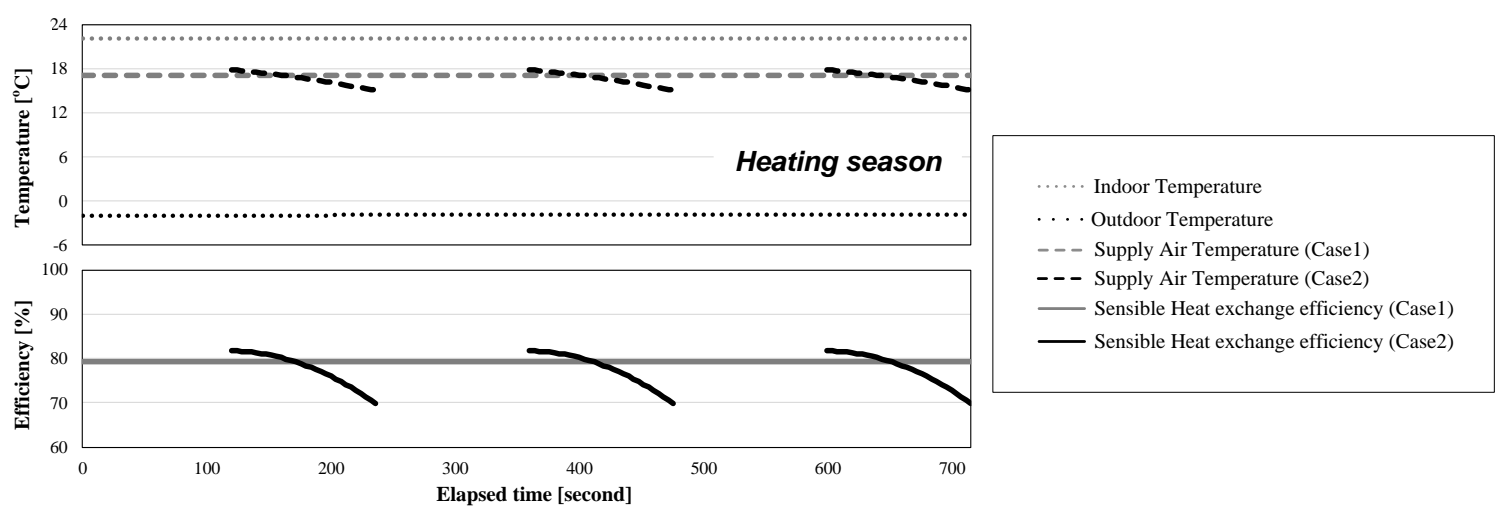

Figure 6 : Variable heat exchange efficiency and Temperature by location - Heating season

determine the air flow rate and direction according to the pressure difference. So it is possible to analyze the airflow rate and direction according to each mode operation(supply process, exhaust process). The designed air supply volume is just the same in both cases. However, in Case2, the final airflow rate due to the increase with infiltration and exfiltration are about $5 \mathrm{CMH}$ higher than Case1, as shown in Figure 7. This means that in case of Case2, unintentional airflow rate is higher than Case1. This is the effect of an increase in pressure differential between internal and external, as a result of the operation of AC ventilation, which operates by separating the supply process and exhaust process repeatedly.

Energy consumption and heating and cooling load of Case1 and Case are compared in Figure 8-9. In heating season, heating load has increased slightly, due to the increase in the infiltration load. As explained above, unintentional ventilation was introduced in the exhaust process during the BdHRV was operating(Case2). Despite the increase in final outdoor air intake and indoor airflow, energy consumption of Case 2 decreased by $8.1 \%$ in heating due to the low Fan operation. And total energy consumption decreased by $19.4 \%$ in cooling season. These results are symbolically indicative of the errors that may be caused by the performance evaluation agency and the simulation methodology that define the performance of the heat exchange ventilation system in a conventional manner.

\section{Conclusion}

In this study, the characteristics and performance evaluation of BdHRV using the concept of alternating current ventilation (AC ventilation) was performed differently from the fixed-plate heat recovery ventilator using the general direct current ventilation (DC ventilation) concept. The efficiency of BdHRV varies with time depending on the characteristics of operating the supply process and the exhast process separately. In addition, simulation method that implements the performance of BdHRV is proposed and quantitatively evaluated the effect on the energy usage when the prescriptive simulation method is applied.

In order to examine the energy usage according to the system operation, it is necessary to precede the step of quantifying the efficiency which varies with time through experiments. The existing ERV system measurement method defines the efficiency at a fixed value in fixed indoor / outdoor temperature / humidity environment. However, in order to measure the efficiency considering the characteristics of BdHRV in this study, it was possible to define the efficiency with time by continuous measurement. The results show that the efficiency varies with time, and this is different by season. The measurement results suggest a problem with the measurement method that defines the performance of various heat exchange ventilation systems as fixed values. In order to implement the performance of BdHRV on a simulation, a different methodology was needed than the existing method of inputting fixed efficiency values 

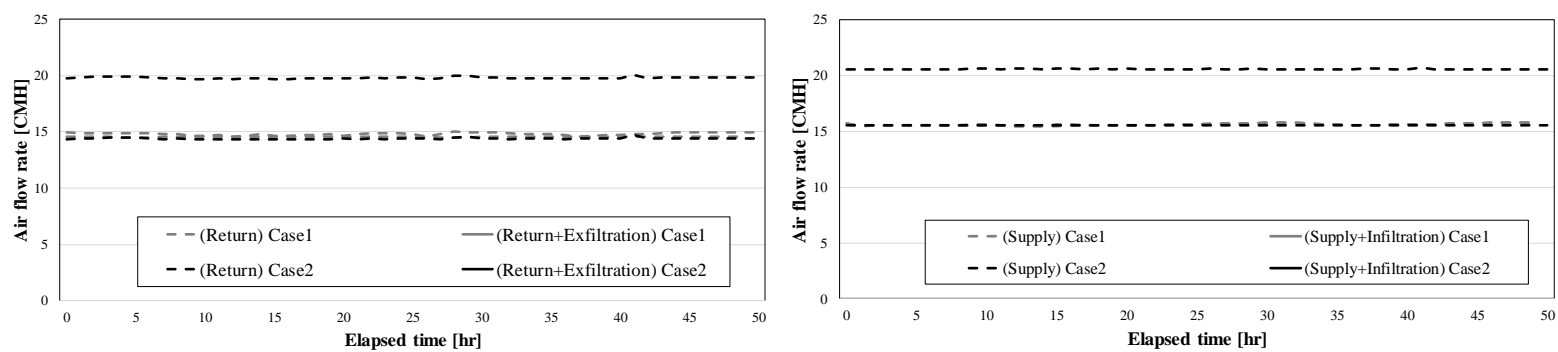

Figure 7 : Comparison of airflow rate with the operation of $H R V$

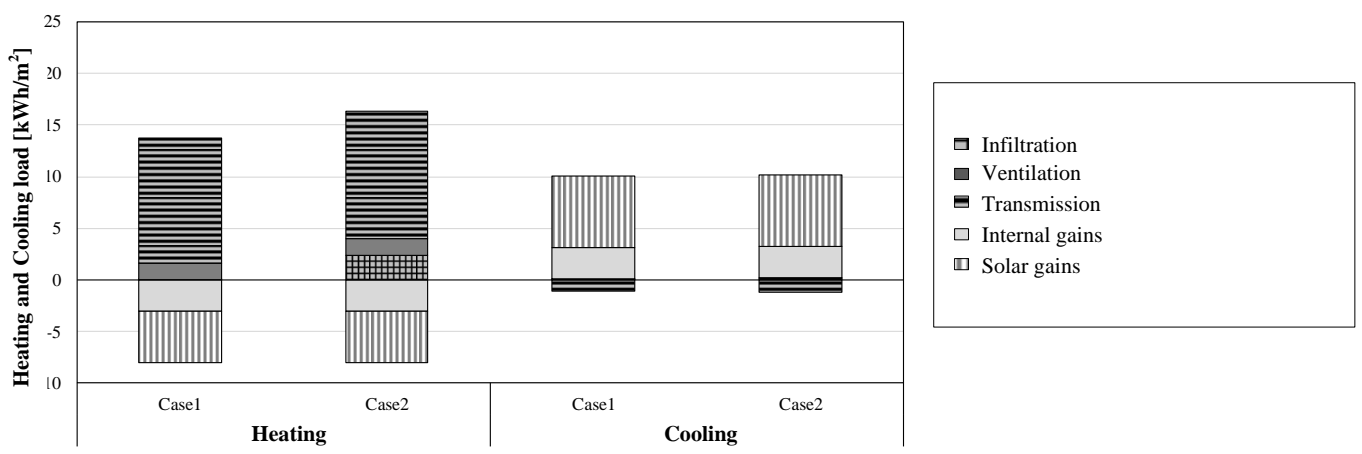

Figure 8: Comparison of heating and cooling load between the two cases

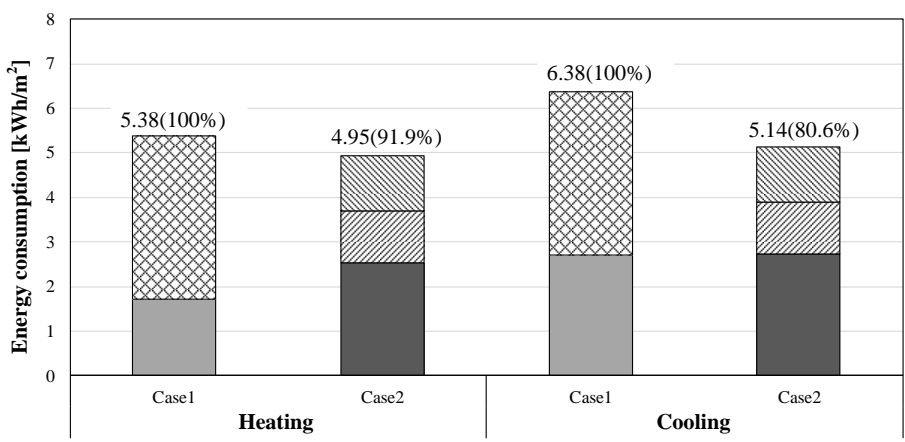

$\square$ Heating energy demand (Case1)

- Heating energy demand (Case2)

Fan operation (Case1)

$\square$ Fan operation (Case2)-Supply process

$\square$ Fan operation (Case2)-Exhaust process

Figure 9 : Comparison of energy consumption between the two cases

directly as input data. Therefore, the variable heat exchange efficiency of BdHRV was newly created and applied to the simulation. In order to implement the characteristics of BdHRV properly, the following two items are considered in the preparation of the simulation model: (1) efficiency that changes with time, (2) the supply mode and exhaust mode are operated periodically according to time Operational logic. Variable efficiency module is implemented through simulations focusing on the exchange efficiency of sensible heat, which changes with time, and the change of supply and exhaust mode at intervals of 120 seconds. The error rate compared with the measured results is about $0.6 \%$. In order to consider the influence of the BdHRV on the characteristics of the separate operation of the exhaust mode and the air supply mode, the air flow of the building was modeled, and the flow direction and the flow rate of the indoor/outdoor air were changed according to the pressure difference.

Finally, the effect of energy consumption on the simulation method was compared. Compared with the results obtained by the prescriptive simulation method, the results of the simulation using the proposed method show that the energy consumption is reduced about $8.1 \%$ in heating season and $19.4 \%$ in cooling season.

Therefore, the characteristics of the heat exchange ventilation system showing the variable efficiency rather than the fixed efficiency according to the operation mode and the material diversification of the total heat exchange ventilation system were confirmed. In addition, it has been confirmed that the efficiency and operation plan should be implemented in consideration of the inherent characteristics of the system rather than simply inputting the fixed efficiency value in the simulation.

As a further study, efficiency of Bi-directional Heat Recovery Ventilation system under real condition and heat transfer issues in duct space will be analysed.

\section{Acknowledgement}

This work was supported by the National Research Foundation of Korea(NRF) grant funded by the Korea government(MSIT) (No. 2018R1D1A1B07047890) and Korea KAIA(Korea Agency for Infrastructure Technology Advancement) in 2018 (No. 18TBIPC144010-01)

\section{References}


AHRI. 2018. "2018 Standard for Performance rating of air to air exchangers for energy recovery ventilation equipment." In.

ASHRAE. 2000. '2000 hvac systems and equipment', ashrae handbook chapter 44.

ASHRAE. 2013. 'Standard 84-2013 (2013). Method of testing air-to-air heat/energy exchangers , atlanta, ga', ASHRAE Standard 84-2013.

ASHRAE. 2016. 'Standard 62.1-2016 (2016). ventilation for acceptable indoor air quality, atlanta, ga', American Society of Heating, Refrigerating and Air-Conditioning Engineers, Inc.

Beattie, Colin, Paul Fazio, Radu Zmeureanu, and Jiwu Rao. 2018. 'Experimental study of air-to-air heat exchangers for use in arctic housing', Applied Thermal Engineering, 129: 1281-91.

Choi, Younhee, Doosam Song, Donghyun Seo, and Joowook Kim. 2018. 'Analysis of the variable heat exchange efficiency of heat recovery ventilators and the associated heating energy demand', Energy and Buildings, 172: 152-58.

Daisey, Joan M., William J. Angell, and Michael G. Apte. 2003. 'Indoor air quality, ventilation and health symptoms in schools: An analysis of existing information', Indoor air, 13: 53-64.

Dieckmann, John, Kurt W. Roth, and James Brodrick. 2003. 'Air-to-air energy recovery heat exchangers', ASHRAE Journal, 45: 57.

El-Baky, Mostafa A. Abd, and Mousa M. Mohamed. 2007. 'Heat pipe heat exchanger for heat recovery in air conditioning', Applied Thermal Engineering, 27: 795801

Fehrm, Mats, Wilhelm Reiners, and Matthias Ungemach. 2002. 'Exhaust air heat recovery in buildings', International Journal of Refrigeration, 25: 439-49.

Han, Hwataik, Kang Kim, Kyung-Jin Jang, Geon-Soo Han, and In-Bok Lee. 2013. 'Energy consumption and indoor environment of broiler houses with energy recovery ventilators', Applied engineering in agriculture, 29: 75159.

Han, Hwataik, and Yong-Il Kwon. 2006. 'Inhaling/exhaling heat recovery ventilator using the concept of alternatingcurrent ventilation', HVAC\&R Research, 12: 843-59.

Hiller, M., S. Holst, T. Welfonder, A. Weber, and M. Koschenz. 2002. 'TRNFLOW: Integration of the airflow model COMIS into the multizone building model of TRNSYS', Transsolar Energietechnik GmbH, Stuttgart.

Huizing, Ryan Nicholas. 2016. "Coated membranes for enthalpy exchange and other applications." In.: Google Patents.

Ireland, prodomo. 'https://www.prodomoireland.com/ductless-hrv/'.

Juodis, Egidijus. 2006. 'Extracted ventilation air heat recovery efficiency as a function of a building's thermal properties', Energy and Buildings, 38: 568-73.

Klein, S. A., W. A. Beckman, J. W. Mitchell, J. A. Duffie, N. A. Duffie, T. L. Freeman, J. C. Mitchell, J. E. Braun, B. L. Evans, and J. P. Kummer. 2009. 'TRNSYS 17', A Transient System Simulation Program.

"KS B 6879-Heat Recovery Ventilators." In. 2017. Korean Standards Association.
Kwon, OhHyun, MinHwi Kim, AnSeop Choi, and JaeWeon Jeong. 2013. 'Energy saving potential of a hybrid ventilation system integrated with heat storage material', Energy and Buildings, 57: 346-53.

Laverge, Jelle, Nathan Van Den Bossche, Nicolas Heijmans, and Arnold Janssens. 2011. 'Energy saving potential and repercussions on indoor air quality of demand controlled residential ventilation strategies', Building and Environment, 46: 1497-503.

Liu, Junjie, Wenshen Li, Jiang Liu, and Bin Wang. 2010. 'Efficiency of energy recovery ventilator with various weathers and its energy saving performance in a residential apartment', Energy and Buildings, 42: 43-49.

Mardiana-Idayu, A., and S. B. Riffat. 2012. 'Review on heat recovery technologies for building applications', Renewable and Sustainable Energy Reviews, 16: 124155.

Nasif, M., R. Al-Waked, G. Morrison, and M. Behnia. 2010. 'Membrane heat exchanger in HVAC energy recovery systems, systems energy analysis', Energy and Buildings, 42: $1833-40$

Nasr, Mohammad Rafati, Melanie Fauchoux, Robert W. Besant, and Carey J. Simonson. 2014. 'A review of frosting in air-to-air energy exchangers', Renewable and Sustainable Energy Reviews, 30: 538-54.

Orme, Malcolm, Martin W. Liddament, and Andrew Wilson. 1998. Numerical data for air infiltration and natural ventilation calculations (Air Infiltration and Ventilation Centre Coventry, UK).

Pan, C. Y., C. D. Jensen, C. Bielech, and H. W. Habgood. 1978. 'Permeation of water vapor through cellulose triacetate membranes in hollow fiber form', Journal of Applied Polymer Science, 22: 2307-23.

Riffat, S. B., and G. Gan. 1998. 'Determination of effectiveness of heat-pipe heat recovery for naturallyventilated buildings', Applied Thermal Engineering, 18: 121-30.

Tamura, George T. 2008. 'Smoke movement and control in high-rise buildings'.

Wargocki, Pawel, David P. Wyon, Yong K. Baik, Geo Clausen, and P. Ole Fanger. 1999. 'Perceived air quality, sick building syndrome (SBS) symptoms and productivity in an office with two different pollution loads', Indoor air, 9: 165-79.

Zhang, L. Z., and J. L. Niu. 2001. 'Energy requirements for conditioning fresh air and the long-term savings with a membrane-based energy recovery ventilator in Hong Kong', Energy, 26: 119-35.

Zhou, Y. P., J. Y. Wu, and R. Z. Wang. 2007. 'Performance of energy recovery ventilator with various weathers and temperature set-points', Energy and Buildings, 39: 